\title{
Colour in Textile Computer-Aided Design Systems
}

\section{Document Version}

Accepted author manuscript

Link to publication record in Manchester Research Explorer

\section{Citation for published version (APA):}

Oulton, D., \& Hawkyard, C. J. (1991). Colour in Textile Computer-Aided Design Systems. Journal of the Society of Dyers \& Colourists, 107, 309-313.

\section{Published in:}

Journal of the Society of Dyers \& Colourists

\section{Citing this paper}

Please note that where the full-text provided on Manchester Research Explorer is the Author Accepted Manuscript or Proof version this may differ from the final Published version. If citing, it is advised that you check and use the publisher's definitive version.

\section{General rights}

Copyright and moral rights for the publications made accessible in the Research Explorer are retained by the authors and/or other copyright owners and it is a condition of accessing publications that users recognise and abide by the legal requirements associated with these rights.

\section{Takedown policy}

If you believe that this document breaches copyright please refer to the University of Manchester's Takedown Procedures [http://man.ac.uk/04Y6Bo] or contact uml.scholarlycommunications@manchester.ac.uk providing relevant details, so we can investigate your claim.

\section{OPEN ACCESS}




\title{
Colour in textile computer-aided design systems
}

\author{
C J Hawkyard and D P Oulton
}

Department of Textiles, UMIST, PO Box 88, Manchester M60 1QD, UK

Current developments in cathode ray tube displays are briefly reviewed. Problems of matching colours on screen displays with actual surface colours are considered, and the viewing surface colours under different illumination conditions is discussed. The principal features of the UMIST Shademaster system are described.

\section{INTRODUCTION}

Anyone who heard or read the paper presented by Rich to the American Association of Textile Chemists and Colorists' conference in Montreal in 1985 [1] would probably have come to the conclusion that the use of a cathode ray tube (CRT) display to represent the appearance of coloured textiles was either impossible, or fraught with almost insurmountable problems. CRTs are notoriously unstable and difficult to calibrate, but the pace of technological development has not slackened, and considerable efforts have been made by a large number of researchers, both industrial and academic, so that today it is possible to be much more optimistic about the prospects in this field.

The first part of this paper will deal with CRT displays, their calibration and the gamut of colours obtainable. Surface colours viewed under one illuminant or another will then be discussed, and the two situations will then be related. In conclusion, after a brief mention of the UMIST Shademaster system, a few pointers to the future will be given.

\section{CRT DEVELOPMENTS}

\section{Phosphors}

Rich discussed the restricted gamut imposed by the use of the traditional additive red, green and blue (RGB) primaries in CRTs. In this regard things have not changed since 1985, and there is unlikely to be any monitor on the market that incorporates a fourth or fifth primary in a CRT.

Most people would admit that they have not noticed any missing colours when watching colour TV, and since the introduction of the red rare earth phosphor in 1964 [2], no major improvements have occurred. The extra cost of including a yellow or purple phosphor, with four or five electron guns, and cameras with the same number of filters, would be exorbitant for what would be a very small increase in gamut. One noticeable difference between CRTs is in the choice of green phosphor. There is a considerable variation, for instance, between the chromaticity of the green phosphor in the Barco monitor and that in the Hitachi monitor, as quoted in Table 1.
Table 1 Chromaticities of Barco and Hitachi primaries

\begin{tabular}{llll}
\hline Monitor & Primary & $x$ & $y$ \\
\hline \multirow{3}{*}{ Barco } & Red & 0.608 & 0.352 \\
& Green & 0.290 & 0.593 \\
& Blue & 0.145 & 0.053 \\
Hitachi & Red & 0.608 & 0.353 \\
& Green & 0.314 & 0.590 \\
& Blue & 0.143 & 0.059 \\
\hline
\end{tabular}

Measurements made with Minolta TV analyser

A problem that has been mentioned [3], but not addressed, is the fall-off in gamut available at low phosphor luminances. Thus on the Hitachi monitor, for example, the restriction on the gamut as measured with the new Minolta TV analyser, which is claimed to be accurate down to $0.2 \mathrm{~cd} / \mathrm{m}^{2}$, is shown in Figure 1 . This adds to the difficulties experienced in displaying deep, saturated

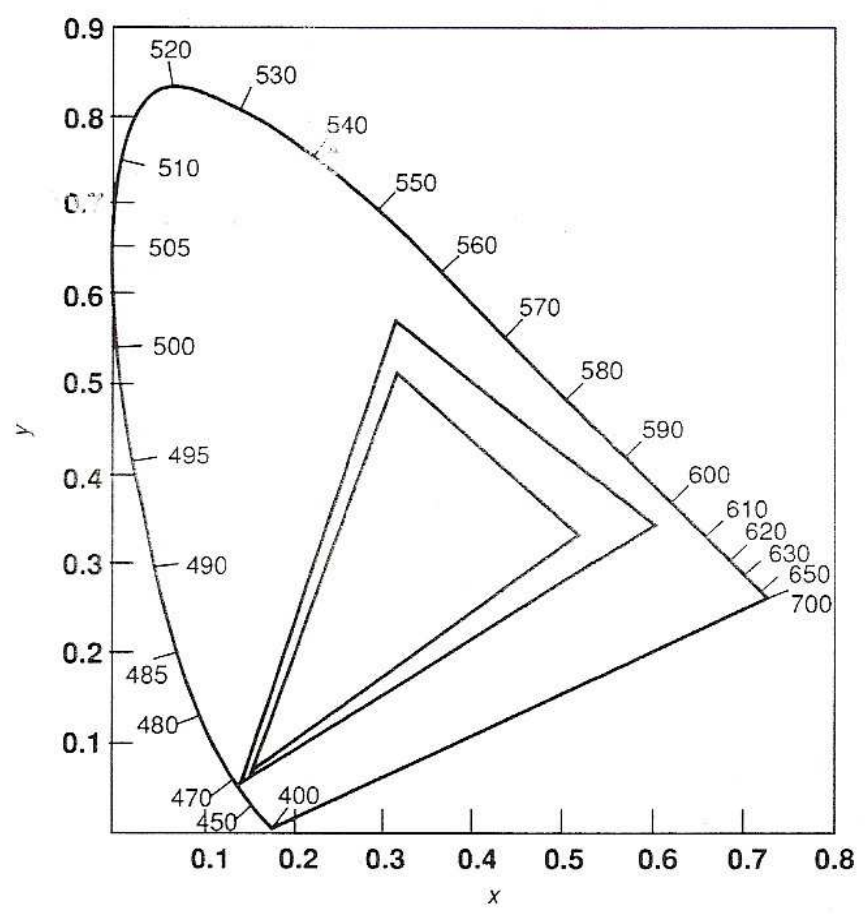

Figure 1 Reduced screen gamut at low luminance (Hitachi monitor) 
colours. Bish [4], in visual matching experiments between textile samples and CRT display, found that of the 37 samples she selected, six could not be matched on the Chromatics CX1400 monitor.

\section{White point}

Rich mentioned that the white point (chromaticity at maximum $R=G=B$ ) of CRTs at that time was usually adjusted to a very high $(9000 \mathrm{~K})$ correlated colour temperature. Since then, however, illuminant $D_{65}$ has become very much the norm $\left(x=0.313, y=0.329,2^{\circ}\right.$ observer $)$.

\section{Ambient lighting conditions}

CRTs are best employed in a darkened room so as to avoid unwanted reflections from the face of the display, due to lighting or daylight. Etched glass screens and various types of filters are sometimes included in an effort to overcome specular reflection problems. In general reflected light desaturates the displayed colours. It is particularly troublesome in aircraft instrument panel displays [5].

\section{CALIBRATION}

The traditional method of calibrating a colour CRT is $\gamma$ correction, which is based on luminance measurements for each primary [6-9]. The method fits power equations to luminance versus gun value (DAC setting) curves in order to provide linear (colorimetric) red, green and blue values. These can be converted to $\mathrm{CIE} X Y Z$ values via matrix equations. A detailed description of $\gamma$ correction and colour transformations is given in a recent review [10].

Despite the evidence presented in one recent paper [9], it must be admitted that simple $\gamma$ correction is not sufficiently accurate, particularly at the bottom end of the luminance scale [3]. The exception is probably the red phosphor, where the rare earth phosphor yields a remarkably good fit for the power equation [9]. The worst fit is for the blue, where the $\gamma$ factor usually requires 1 ifting at low luminances.

Post and Colhoun [3] concluded that piecewise linear interpolation is the most accurate approach to calibration, but used an iterative routine to correct test colours each day. This points the way to on-line calibration, the method now used for the Shademaster system.

\section{THE SCALING OF LUMINANCE}

Although luminance readings are absolute, CIE tristimulus values are not. Luminance is directly proportional to $Y$, since both depend on the $V_{\lambda}$ curve. At UMIST a luminance factor' is used which defines the $Y$ value of the white point of the monitor $(R=G=B=255)$. Thus if the luminance factor is set at $100, Y$ for the white point is 100 . Assuming the monitor white point appears brighter than a white viewed in an adjacent matching cabinet, the luminance factor will need to be greater than 100 . If this is not the case, the lighting level in the cabinet should be reduced.

\section{DISCREPANCIES IN LUMINANCE ASSESSMENT}

The $V_{\lambda}$ curve for the $2^{\circ}$ observer dates from 1924 [11], and is the basis for the measurement of luminance in photometers, luminance meters, colorimeters, spectrophotometers and spectroradiometers. It was not until 1951 that Judd, in a CIE report [12], suggested that the curve was too low at short wavelengths. Vos [13] subsequently published a similar revision, and recently the CIE have issued new recommendations [14]. The data illustrated in Figure 2 is recommended for use in visual matching experiments and for 'luminance measurement of displays on a colour video monitor'. Instrument manufacturers must surely grasp the nettle eventually. The $10^{\circ}$ curve for $y$ [15] was verified in 1964, and also exhibits a bulge to the left in comparison with the 1924 curve.

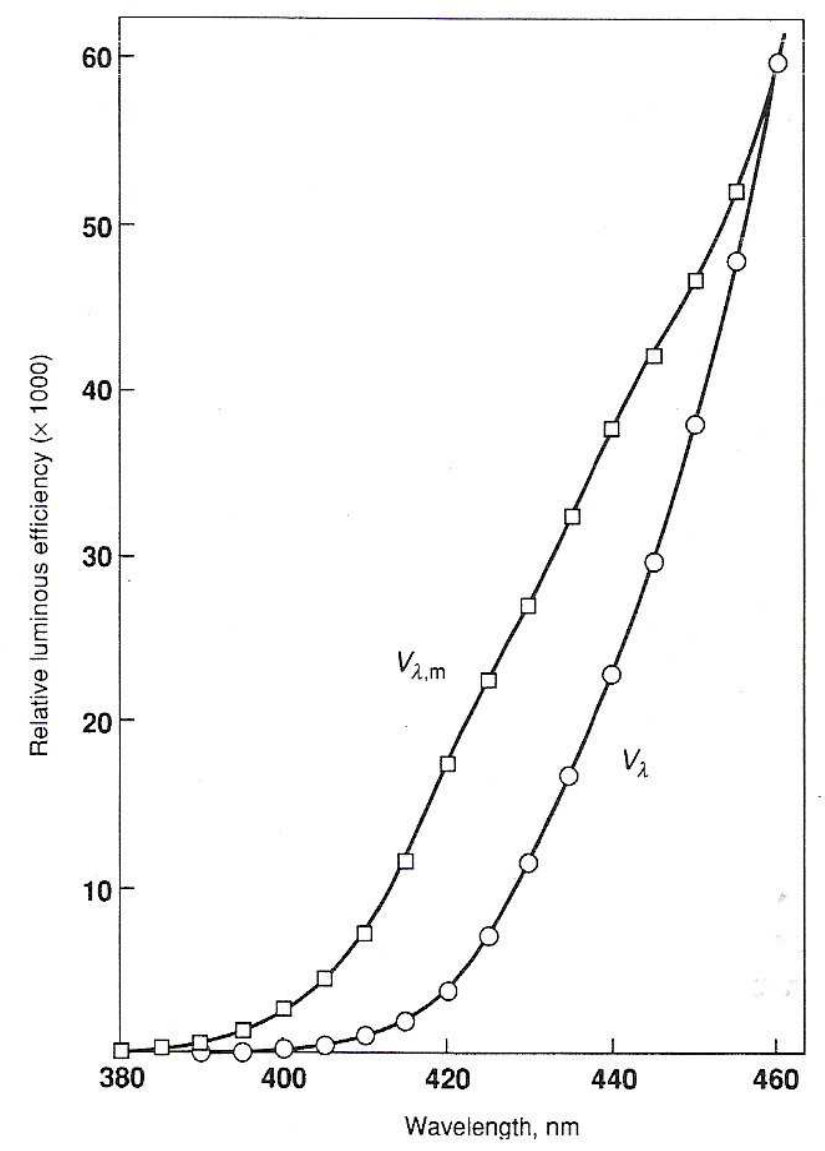

Figure 2 Bulge in the $V_{\lambda}$ curve (Figure 2 in ref. 16)

Kinney [16] has pointed out that the buige, while not making a significant difference to luminance assessment for continuous white sources, will affect blue stimuli greatly. The measured luminance of the biue primary in VDUs will be much higher, for example. Another possible cause of discrepancies mentioned by Kinney is the fact that at low light levels the rods in the retina come into play. The scotopic spectral efficiency curve $V_{\lambda}{ }^{\prime}$ is displaced to shorter wavelengths compared with $V_{\lambda}$ and there is also a range of brightness over which both rods and cones are active (mesopic vision). Since this lies in the region between $10^{-3}$ and $3 \mathrm{~cd} / \mathrm{m}^{2}$ [17], luminance assess- 
ment, particularly for the red and blue primaries, will be affected for dark colours.

\section{MATCHING SCREEN COLOURS TO SURFACE COLOURS}

Several workers $[1,4,18,19]$ have carried out visual matching experiments between physical samples viewed under a particular illuminant and colours displayed on a VDU. For the best results the screen should be masked, a hole cut into it, and a light box sited immediately adjacent to the hole. The illuminated sample is then placed up against the side of the box next to the hole so that the gap between the screen colour and the surface colour is minimal (Figure 3) [4].

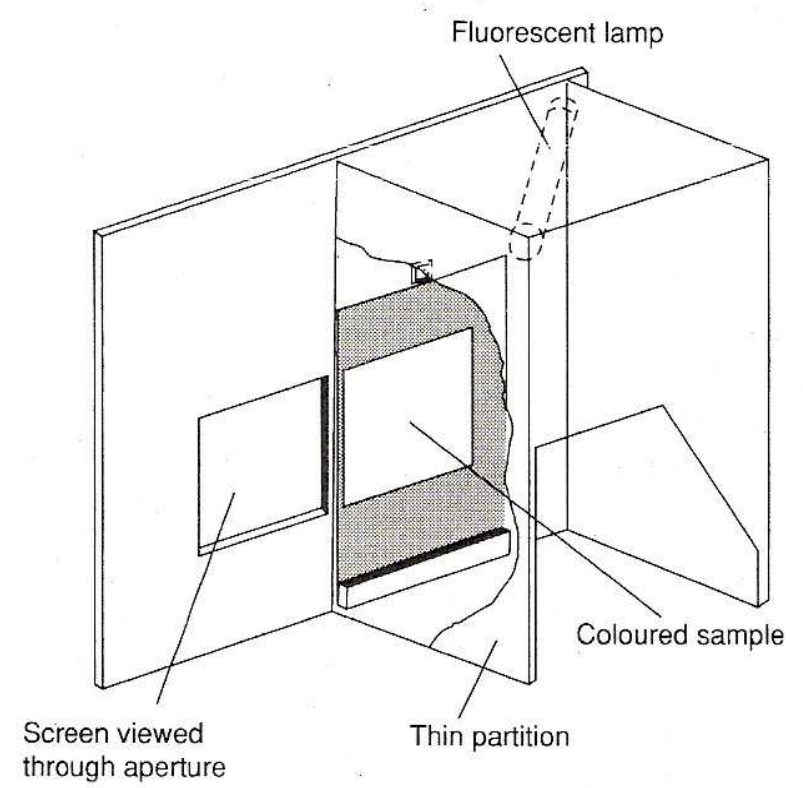

Figure 3 Mask for visual matching

Though stating the obvious, it is as well to remember that what we see is governed by the spectral composition of the light entering our eyes. Light from the VDU is defin d, therefore, by its spectral power distribution (SPD). The SPD of white light from the Hitachi monitor is shown in Figure 4. The 'spiky' nature of the curve at the higher visible wavelengths is due to the rare earth red phosphor. When light from a source is not viewed directly, but only after it has been reflected off a coloured surface,

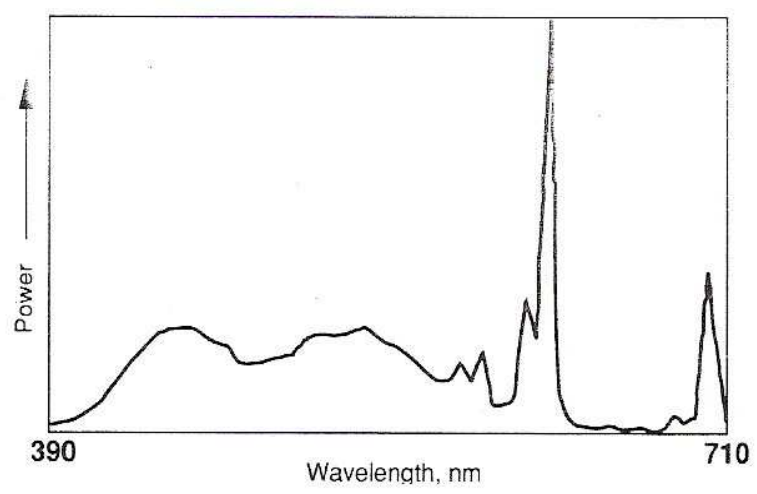

Figure 4 SPD of monitor white the SPD of the light source is modified in accordance with the reflectance curve of the surface. It is essential to remember that the reflectance curve of a surface is independent of the light source (a fundamental law in colour physics that is rarely emphasised sufficiently).

This preamble leads up to the point that the colour viewed on the VDU can be regarded as matching a surface colour under any illuminant the viewer chooses. Tarrant et al. [18] used tungsten (CIE illuminant A), while Bish and Wilkinson [19] used a fluorescent tube. At UMIST a program has been written to display the Munsell colours stipulated under illuminant $\mathrm{C}$.

\section{COLOUR CONSTANCY AND VISUAL ADAPTATION}

Human beings are not good at judging colours in isolation, but instead use the surrounding colour or colours to help in their assessment. Simultaneous contrast can have a marked effect, in terms of both lightness and hue, and this applies to VDU displays as well as to surface colours. We recommend a neutral grey background with a lightness (brightness for VDUs) half way between black and white. With VDUs it is often a good idea to include a reference white and black. Here the reader should remember that the human perception of the grey scale is non-linear, and that a mid-grey has a $Y$ value of about 20 , not 50 as might be expected.

When a physical sample with a known reflectance curve exists, it is a simple matter to calculate the CIE tristimulus values under any illuminant for which weighting factors are available. After transformation from $X Y Z$ to $R G B$ the colour can then be displayed on a VDU. The match obtained between the screen colour and the physical sample viewed under the daylight tube is generally good, provided the monitor has been calibrated and the correct luminance factor has been used.

When $X Y Z$ under daylight were recalculated for the surface colour under illu ninant A (tungsten), and the background altered using the $X Y Z$ values for a grey under the same light, the appearance of the associated screen colpur $\mathrm{r}$ was vastly different to the displayed colour for the surface under daylight. This is hardly surprising, since the maximum $Z$ value for source $A$ is 35 . Everything appears to be much yellower under tungsten, but nowhere near as yellow as they appeared on the screen. The brain soon adapts to different illuminants, as is shown spectacularly by Hunt's famous demonstration (see Appendix). The calculated colours may be correct for a fraction of a second, but after adaptation they usually revert to the same colours as they had under daylight. Several attempts have been made to quantify chromatic adaptation [20,21], but this is a field ripe for further research [22].

\section{METAMERISM}

The colour difference between two surface colours can be readily calculated for a specified illuminant, and this data is a useful guide to metamerism. However, colours displayed on a monitor for which no reflectance data are 
available, i.e. they do not refer to an equivalent physical sample, cannot have their tristimulus values recalculated for a different illuminant. The best guide to colour constancy for surface colours is probably change in CIELAB hue angle $\left(\tan h=b^{*} / a^{*}\right)$, the origin being the illuminant point for every illuminant, but again this cannot be calculated for screen colours when no equivalent physical sample exists.

\section{SYNTHETIC REFLECTANCE CURVES}

The UMIST Shademaster system incorporates the concept of a pseudo or synthetic reflectance curve for a screen colour when no physical sample exists. Colours that have been selected and altered on the VDU can then have a reflectance curve calculated for them, which allows physical samples to be produced via computer match prediction. The computer program developed to calculate the synthetic reflectance curve proceeds via tristimulus match prediction using very pure primaries. Very few surface colours have been found for which a synthetic reflectance curve cannot be calculated, the gamut being larger than the screen gamut on the Hitachi monitor. CIELAB hue angle can be calculated from the synthetic reflectance data, and colour constancy is good by comparison with most recipes obtained for real colorants. The real and synthetic reflectance curves for a green garment are shown in Figure 5.

\section{THE SHADEMASTER SYSTEM}

The system aims to exploit the facility of precise onscreen colour, which is reproducible from system to system and over time. It has been developed as a tool for designers who create and specify colour ideas.

The essential elements of the Shademaster system are as follows:

(a) a visual display which represents a complex scene; this simulates the interior of a matching cabinet in layout, and in apparent illumination

(b) an on-line monitor calibration system which establishes and maintains constant colour reproduction; colours are maintained to \pm 0.005 in CIE $x$ and $y$, and $\pm 1 \%$ in $Y$, from system to system, and over tirie on one system

(c) an ability to specify all colours on screen in terms of their CIE $L^{*} a^{*} b^{*}$ and $X Y Z$ coordinates

(d) a system for generating a 16 point (or more) synthetic reflectance curve for colours generated on screen

(e) a comprehensive set of colour manipulation tools, which allow single colours and groups of colours to be modified and moved around

(f) an easy-to-use, point-and-select, man-machine interface, allowing designers to interact freely and directly with the colour creating facilities.

\section{Colour manipulation tools}

The on-screen visual presentation includes a total of 25 simulated colour tiles. Some of the tiles are associated into 'colourways', which appear to consist of overlapping samples, and allow colour relationships to be examined.

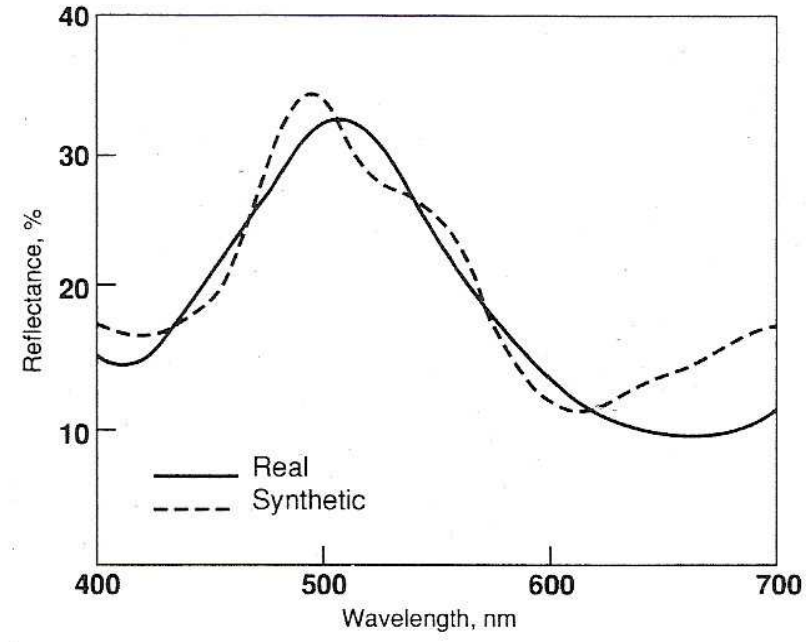

Figure 5 Real and synthetic reflectance curves for green garment

Individual colours and groups of colours can be moved easily from tile to tile. They can also be stored to, and retrieved from, file, and can be associated with a name.

A colour range facility allows any two colours to be selected, and a range of intermediate colours produced. The system is capable of colour gradation steps of less than a just-visible difference over most of colour space.

The point-and-select (mouse) user interface largely eliminates the need for keyboard use. It aims to allow the colourist to interact freely with the colour manipulation and specification tools provided.

It must be noted that the relative perceptual uniformity of $L^{*} a^{*} b^{*}$ space greatly aids the colour manipulations just described, and that the system makes an interesting application of the uniform colour space concept.

\section{Colour reproduction accuracy}

A representative set of 40 test colour specifications has been used to test the accuracy of reproduction of CIE specifications by the system. The screen colour was measured with a Minolta CA 100 colour analyser. The results are summarised in Table 2 . The test colours were selected from Munsell colour space as follows:

\section{Set 1}

1. ten neutrals from $V=1$ to $V=10$

2. a hue circle at $V=2 \mathrm{C}=4$

3. a hue circle at $V=5 C=6$

4. a hue circle at $V=8 C=6$

Table 2 Test results on accuracy of colour reproduction of Shademaster system

\begin{tabular}{lllll}
$\begin{array}{l}\text { Average } \\
\text { deviation }\end{array}$ & & & \multicolumn{2}{l}{$\begin{array}{l}\text { Maximum } \\
\text { deviation }\end{array}$} \\
\cline { 1 - 1 } \cline { 5 - 6 } & $y$ & & $x$ & $y$ \\
0.0018 & 0.0023 & & 0.003 & 0.004 \\
0.0037 & 0.0058 & & 0.009 & 0.015 \\
0.0020 & 0.008 & & 0.004 & 0.007 \\
0.0024 & 0.0013 & 0.006 & 0.002
\end{tabular}




\section{FUTURE TRENDS}

Although a great deal of effort is being put into alternatives to CRTs for colour displays, particularly liquid crystal displays, it seems unlikely that a major change will occur in the next few years. The graphics cards that control colour CRTs are being rapidly upgraded, with higher resolution and more simultaneous colours resulting. Calibration techniques have progressed well beyond simple $\gamma$ correction, and a so-called self-calibrating monitor is now available [23].

At UMIST we have interfaced a Macbeth spectrophotometer to the computer-aided design system so that colours can be measured into the system directly. Colours selected on screen can have a synthetic reflectance curve determined for them via the Shademaster software, and the data is transferred to a file accessed by the computer match prediction system hosted by the same computer. Textile or other materials can then be produced in colours that match those displayed on the monitor [24]. Hard copy produced on an ink-jet paper printer attached to the computer-aided design system does not reproduce the displayed colours accurately, but rapid progress is likely in this field.

\section{* $\quad * \quad$ *}

The early stages of the research carried out at UMIST were supported by SERC (ACME) Division, Pragma Ltd, St. Albans, and Parkland Manufacturing Co. Ltd, Bradford. Subsequently we have been greatly assisted by $\mathrm{Mr}$ S J Reyner.

\section{REFERENCES}

1. D C Rich, Text. Chem. Colorist, 18 (6) (1986) 16.

2. RGHunt, The reproduction of colour, 3rd Edn(London: Fountain Press, 1975) 437.
3. D L Post and C S Calhoun, Col. Res. Appl., 14 (1989) 172.

4. R C Bish, MSc thesis (UMIST, 1988).

5. J Laycock, J. Inst: Electron. Radio Eng., 56 (1986) 96.

6. WNSproson, Colour science in television and display systems (Bristol: Adam Hilger, 1983).

7. W B Cowan, Computer Graphics, 17 (1983) 315.

8. W B Cowan, Notes for a course presented at the annual meeting of Optical Society of America, Rochester (Oct 1987).

9. C J Hawkyard, and C Wilkinson, J.S.D.C., 106 (1990) 356; 107 (1991) 83.

10. C J Hawkyard, Rev. Prog. Coloration, 21 (1991) 00.

11. K S Gibson and E P T Tyndall, Compte Rendu, Geneva (1924)67, 232.

12. D B Judd, CIE proceedings (Stockholm, 1951) Vol. 5 (part 7) 11.

13. J J Vos, Col. Res. Appl., 3 (1978) 125.

14. P K Kaiser, CIE Publication No. 86 (1990).

15. W S Stiles and J M Burch, Results in CIE Publication No. S002 (1986).

16. J A S Kinney, Col. Res. Appl. 8 (1983) 82.

17. CIE Publication No. 41 (TC-1.4) (1978).

18. A W Tarrant, S Brown and J Laycock, Displays, (7) (1983) 162.

19. CWilkinson, Unpublished work.

20. C J Bartleson, Col. Res. Appl., 4 (1979) 143.

21. Y Nayatani et al., Col. Res. Appl., 9 (1984) 106.

22. M H Brill and G West, Col. Res. Appl., 11 (1986) 196.

23. A Bellini, Pixel, 9 (1988) 49.

24. C J Hawkyard and C Wilkinson, Computer recipe prediction for colours selected on a monitor, SERC ACME Div. Conf. (Nottingham University, 1988).

\section{APPENDIX}

\section{Hunt's famous demonstration}

A slide showing a multi-coloured scene including a yellow cushion was shown. Next a duplicate of the same slide with a blue filter over the cushion was shown, and the cushion looked green. Finally another duplicate had the blue filter superimposed over the whole slide and the cushion then appeared to be yellow again, despite the fact that the same stimulus appeared green when surrounded by the original background. 
